\title{
Initial manifestation of parotid extra-medullary myeloma in an HIV positive patient on anti-retroviral therapy: A case report and review of the literature
}

\author{
SHIVESH MAHARAJ ${ }^{1,2}$ and SHEETAL MUNGUL ${ }^{1}$ \\ ${ }^{1}$ Department of Otorhinolaryngology/Head and Neck Surgery, Charlotte Maxeke Johannesburg Academic Hospital, \\ University of The Witwatersrand, Johannesburg 2193; ${ }^{2}$ Department of Otorhinolaryngology/Head and Neck Surgery, \\ Charlotte Academic Hospital, University of The Witwatersrand, Johannesburg 2150, South Africa
}

Received September 23, 2019; Accepted June 12, 2020

DOI: 10.3892/br.2020.1335

\begin{abstract}
Multiple myeloma is a biologically diverse, malignant disease that involve plasma cells. Multiple myeloma is characterized by the unrestrained proliferation of monoclonal plasma cells within the bone marrow. In the present case report, the case of a human immunodeficiency virus (HIV) positive patient with an initial manifestation of extramedullary myeloma involving the parotid gland is described. The patient had been on antiretrovirals for the last two years. A Medline, Embase, Scopus and Google Scholar search was performed using the key words: 'Parotid extramedullary myeloma AND HIV' as part of the literature review. A 46-year-old female presented to our hospital with a 6-month history of a painful mass on the left side of the face, involving the parotid area, with rapid growth in the preceding month. There was associated fever, body pains and difficulty opening the mouth. This resulted in difficulty in mastication and she also reported pain on swallowing. She did not notice any weakness of her face on the left side. She had no complaints regarding her eyes, such as visual disturbances, eye pain, or an inability to close the eye on the affected side. The patient was diagnosed with HIV infection 2 years prior, and had been on highly active antiretroviral therapy (HAART) since the diagnosis. There is no consensus regarding a treatment protocol for HIV positive patients on HAART and multiple myeloma. However, based on the clinical case report and a review of the relevant literature, the treatment should include high doses of a combination of chemotherapeutic agents. Although multiple myeloma is
\end{abstract}

Correspondence to: Dr Shivesh Maharaj, Department of Otorhinolaryngology/Head and Neck Surgery, Charlotte Maxeke Johannesburg Academic Hospital, University of The Witwatersrand, 7 York Road, Parktown, Johannesburg 2193, South Africa

E-mail: shivesh.maharaj@wits.ac.za

Key words: multiple myeloma, head and neck, human immunodeficiency virus considered incurable, all patients should be started on treatment with the goal of preventing further complications.

\section{Introduction}

Multiple myeloma is a biologically diverse, malignant disease involving the plasma cells. The condition is characterized by the unrestrained proliferation of monoclonal plasma cells within the bone marrow $(1,2)$.

Plasma cells develop from $B$ cells which arise from the white blood cells as part of the immune system, and function in the production and regulation of antibodies (2). Aberrations in the development of plasma cells results in malignant diseases, which in turn results in overproduction of non-functional immunoglobulin (Ig) chains or intact Igs (3). The monoclonal IgM protein that is found in the serum or urine of patients with multiple myeloma is due to the uncontrolled proliferation of myeloma cells (3). Specific heavy and light chain Ig classes can be determined by electrophoresis, and immune-electrophoresis or immunofixation techniques (3).

The criteria for diagnosis of myeloma include the following: i) Urine or serum IgM-protein levels $\geq 30 \mathrm{~g} / \mathrm{l}$; ii) myelogram showing a population of plasma cells $\geq 10 \%$ : iii) Monoclonal plasma cells present in bone marrow biopsies; and iv) evidence of end-stage organ damage, such as hypercalcaemia, renal dysfunction, anaemia, osteolytic bony lesions or extramedullary manifestations of myeloma (3-5). The majority of patients $(>90 \%)$ with multiple myeloma present with $\operatorname{IgM}$-proteins in the serum or urine at the initial presentation $(6,7)$.

At the time of diagnosis extramedullary manifestations of myeloma are uncommon. There are different variants of myeloma, namely solitary bone plasmacytoma which is characterized by localized disease, and extramedullary plasmacytoma which involves soft tissue outside the skeletal system $(6,7)$.

It is important to differentiate myeloma from other pathologies such as plasmablastic lymphoma, plasma cell leukaemia and monoclonal gammopathies. Human immunodeficiency virus (HIV) positive patients suffer from immune dysregulation, and as a result, may have an increased risk of malignancies, such as myeloma and lymphoma. A study 
published in Brazil found that there were greater numbers of neoplasias (25.1 vs. $15.9 \%$, respectively) and lymphoid neoplasias ( 6.2 vs. $2.4 \%$, respectively) in HIV positive patients following anti-retroviral therapy (ART) than before the patients were prescribed ARTs (8).

In the present case report, an HIV positive patient with an initial manifestation of extramedullary myeloma involving the parotid gland is described. The patient had been on ARTs for 2 years. Additionally, Medline, Embase, Scopus and Google Scholar were searched using the key words: 'Parotid extramedullary myeloma AND HIV' as part of the literature review.

\section{Case report}

The present study was performed in accordance with the University of the Witwatersrand Human Research Ethics protocol. Written consent was obtained for the publication of this case report and any accompanying images.

A 46-year-old female presented Charlotte Maxeke Johannesburg Academic Hospital with a 6-month history of a painful mass on the left side of the face, involving the parotid area, with rapid growth in the preceding month. There was associated fever, body pains and difficulty opening the mouth. This resulted in difficulty in masticating and she also reported pain on swallowing. She did not notice any weakness of her face on the left side, or complain of any visual problems, such as visual disturbance, eye pain or an inability to close the eye on the affected side. The patient was diagnosed with HIV infection 2 years prior and had been on highly active antiretroviral therapy since then. The therapeutic regimen for HIV consisted of a single fixed dose combination tablet of Tenofovir (300 mg), Emtricitabine (200 mg) and Efavirenz $(600 \mathrm{mg})$ daily. There was no history of previous head and neck malignancy or tuberculosis infection.

Clinical examination revealed a large, $\sim 8 \times 10 \mathrm{~cm}$ left parotid mass, extending to the left side of the neck. The mass was firm, fixed to underlying structures and tender on palpation. The overlying skin was intact. The sizeable mass resulted in loss of the nasolabial fold on the affected side; examination of the nose showed no presence of a tumour within the nasal cavity and central position of the nasal septum. There was associated trismus with visible intraoral extension of the tumour, as the mucosal-covered soft tissue mass appeared to be growing from the maxillary area on the left side. There was medialisation of the left tonsil. However, there were no signs of acute airway compromise. The facial nerve was intact and there were no features of orbital extension of the mass such as proptosis or loss of visual acuity. The rest of the cranial nerve examination was essentially normal. There were no neck nodes palpable (Fig. 1).

Plain X-ray revealed multiple osteolytic lesions involving the skull. A contrast computed tomography scan showed a large, solid, fairly well circumscribed left neck mass, which extended to the skull base superiorly and inferiorly to the hyoid bone (Figs. 2, 3 and 4).

The mass was $\sim 8.0 \times 8.2 \times 10.0 \mathrm{~cm}$ in size. The left masseter muscle and left parotid gland was indistinguishable from the mass and inseparable from the sternocleidomastoid muscle posteriorly. There was no encasement by the mass of any major

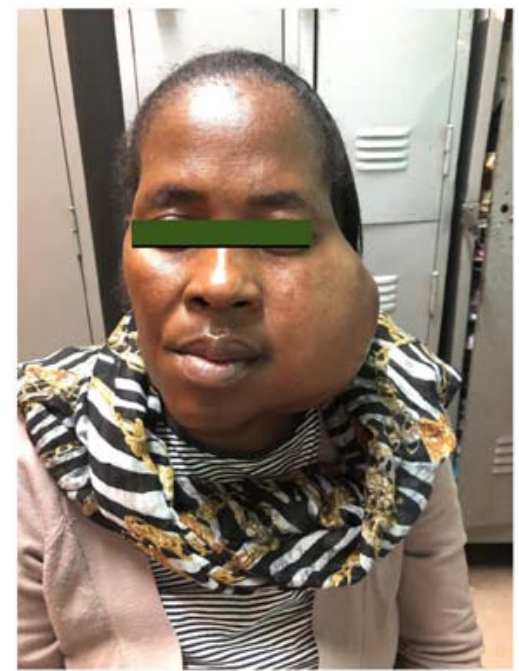

Figure 1. Patient with a large left parotid mass.

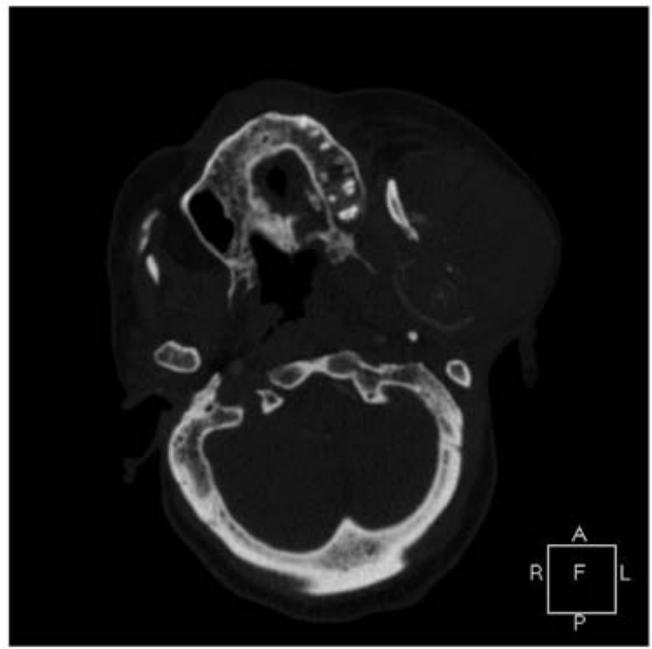

Figure 2. Axial computed tomography scan demonstrating the large, solid, fairly well circumscribed left neck mass. A, axial; R, right; P, posterior; $\mathrm{L}$, left; F, frontal.

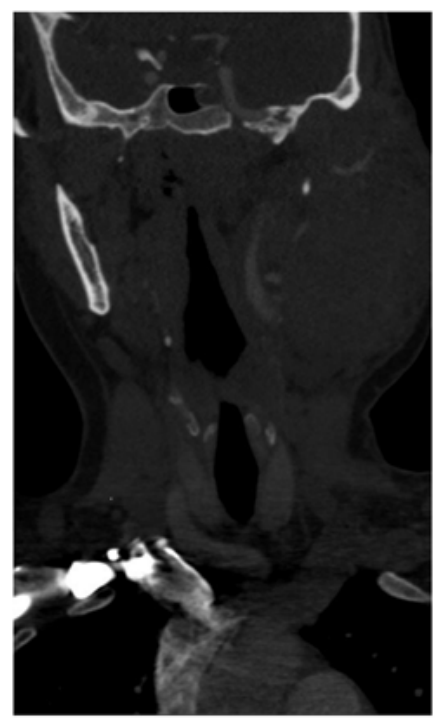

Figure 3. Coronal computed tomography showing parotid mass extending from the skull base superiorly to the hyoid bone inferiorly. 


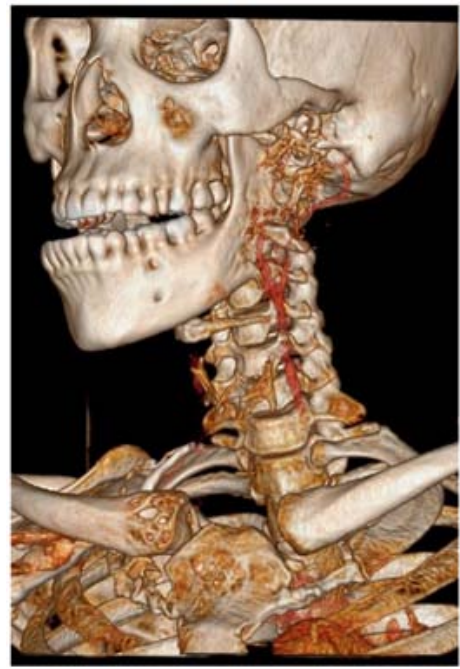

Figure 4. Three-dimensional reconstruction showing multiple lytic bony lesions.

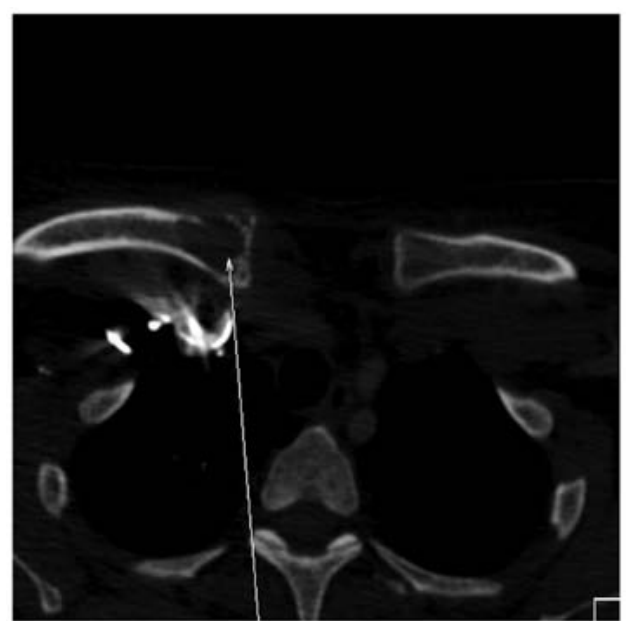

Figure 5. Computed tomography scan showing a lytic lesion (arrow) of the clavicle.

neck vessels. There was significant erosion and destruction of the underlying left ramus of the mandible, and lytic lesions involving the ribs, sternum, clavicle, and vertebrae (Fig. 5). There was associated significant ipsilateral neck nodes. Thus, a malignant neoplasm involving the parotid gland was suspected.

A fine needle aspirate of the parotid mass showed the presence of numerous plasma cells, suggestive of plasma cell dyscrasia. A haematologist was consulted, and a suspicion of multiple myeloma was raised based on the multiple bony lytic lesions. Blood results showed a low haemoglobin level of $9.8 \mathrm{~g} / \mathrm{dl}$, a white blood cell count of $5.6 \times 10^{9} / 1$, a platelet count of $278 \times 10^{9} / 1$, serum calcium levels of $2.23 \mathrm{mmol} / 1$, serum phosphorous levels of $1.22 \mathrm{mmol} / \mathrm{l}$, urea levels of $2.2 \mathrm{mmol} / \mathrm{l}$ and creatinine levels of $60 \mu \mathrm{mol} / 1$. The CD 4 count was 519 cells $/ \mu 1$. The total serum protein concentration was high (98 g\l) and albumin concentration was low $(31 \mathrm{~g} / \mathrm{l})$.

There was an abnormal serum free light chain assay result with a free $\kappa$-light chain concentration of $40.9 \mathrm{mg} / \mathrm{l}$ and a free $\lambda$-light chain concentration of $245 \mathrm{mg} / 1$, with a $\kappa: \lambda$ ratio of 0.17 ; thus, increased paraprotein levels were detected. A monoclonal band of $\operatorname{IgG} \lambda$ was detected on immunofixation. Protein electrophoresis demonstrated paraprotein levels of 1 in $32 \mathrm{~g} / \mathrm{l}$, with a monoclonal band present in the $\gamma$ region.

Urine analysis was therefore performed which revealed monoclonal (Bence-Jones) paraprotein levels $>30 \mathrm{~g} / \mathrm{l}$. Urine immunofixation electrophoresis demonstrated increased free $\lambda$ chain levels.

Bone marrow aspirate showed plasmacytosis comprised $12 \%$ of the myelogram. There was no increase in the number of blast cells. The plasma cells were mature, and some cells were binucleated. There were left shifted neutrophils, indicative of a deficiency in vitamin B12 or Folate, and erythropoiesis was decreased. Trephine biopsy was deemed inadequate for histological evaluation.

Cytogenetic evaluation showed a normal female karyotype of 46XX. Core biopsy of the parotid mass demonstrated cores comprising a malignant neoplasm seen infiltrating into the soft tissue. There was focal representation of parotid salivary gland parenchyma. The neoplasm was arranged in sheets of markedly pleomorphic and mature plasmacytoid cells. The neoplastic cells were enlarged and contained bizarre cellular and nuclear morphological features. The nuclei were eccentrically placed with dense chromatin and prominent nucleoli. There was abundant amphophilic cytoplasm. Examination in 10 high-power fields revealed 6 mitotic characteristics and immunohistochemistry analysis of the specimen was used to show these characteristics: -LCA, which highlights reactive lymphocytes; -CD3, which highlights reactive T-cells; -CD38, where positive staining indicates tumour cells; -CD138, where positive staining indicates tumour cells; -Cyclin D1, where positive nuclear staining of tumour cells; -Ki67, where positive staining indicates a proliferation index $>60 \%$. Fluorescent in situ hybridization showed $\lambda$-light chain restriction.

These findings were therefore consistent with a diagnosis of multiple myeloma, Durie-Salmon stage IIIA (5). The patient was referred to the Medical Oncology unit for chemotherapy. She was prescribed 7 cycles of Melphalan $9 \mathrm{mg} / \mathrm{m}^{2}$ per Os day 1-4 and Prednisone $100 \mathrm{mg}$ per Os day 1-4. This was repeated every 4 weeks. A total of 2 months after initiation of chemotherapy, she reported to have been tolerating the treatment well. There was marked clinical reduction in the size of the parotid mass, which now measured $4 \times 3 \mathrm{~cm}$ and chemotherapy was continued. Trismus and difficulty in mastication was reduced and there was no longer visible intraoral extension of the mass on examination. Unfortunately, the patient was lost to long-term follow up and it is unclear whether the patient had a complete response to treatment or relapsed as a result of defaulting the treatment.

\section{Literature review}

Multiple myeloma accounts for $1 \%$ of all types of cancer and $10 \%$ of all haematological cancers $(6,7)$. It is slightly more common in males, and was found to be more common in African Americans compared with Caucasians (8). At the time of diagnosis, $1-2 \%$ of patients present with the condition occurring outside the bone marrow, and $8 \%$ of the patients develop extramedullary manifestations during the course of the disease with a median age of presentation of 72 years $(9,10)$.

HIV results in immunodeficiency that predisposes patients to a variety of disorders, including plasma cell disorders (11). 
Studies have shown a 4.5 -fold increased risk of multiple myeloma in patients infected with HIV, with the presentation being more aggressive and disseminated compared with patients who were not co-infected with HIV $(11,12)$.

There is an increased incidence of multiple myeloma in patients with HIV/acquired immune deficiency syndrome according to Grulich et al (13). The pathophysiology underlying the development of plasma cell disorders is unclear, but may be associated with chronic antigenic stimulation from HIV and other viral co-infections, elevated serum IL-6 levels and Epstein-Barr virus-driven proliferation of infected B cells (14-16).

HIV infection is a risk factor for both aggressive clinical behaviour and unusual clinical presentation of extramedullary myeloma cases. de Camargo Moraes et al (17) described a case of an HIV positive patient that presented with swelling of the palate, and left gingival fornix in the maxilla confirmed the diagnosis with well-differentiated plasma cells and restriction of the $\lambda$-light-chain. A retrospective cohort study, performed in a single centre, reported that HIV-positive patients presented with multiple myeloma at a significantly younger age, and presented with less osteolytic lesions, renal impairment, and lower neutrophil counts (18). All HIV-positive patients presented with paraproteins of the IgG subtype, suggesting a possible relationship between multiple myeloma and an $\mathrm{IgG}$ response to HIV antigens (18). The patients had significantly increased CD4 counts, with a low prevalence of abnormal free $\kappa / \lambda$ ratios (18). The study further showed that HIV co-infection did not significantly affect the stage of the disease multiple myeloma presented at, nor did it affect the incidence of pathological fractures, bone marrow plasmacytosis or changes in the lymphocytic counts (18).

Cauda et al (19) suggested that HAART may lead to a reduction in IgM-proteins in certain HIV-infected patients with monoclonal gammopathy. Additional studies are required to determine whether HAART treatment may delay the progression from monoclonal gammopathy to plasma cell malignancy.

There have been reports that HAART alone can lead to the complete remission of smouldering multiple myeloma, however there are no accepted guidelines for managing HIV positive patients with multiple myeloma (20). This is due to the paucity of clinical data and HIV positive patients with multiple myeloma being excluded from clinical trials.

In conclusion, there is no consensus regarding a treatment protocol for HIV positive patients receiving HAART who present with multiple myeloma. However, based on the present clinical case report and a review of the relevant literature the treatment should include high dose chemotherapy agents. Although multiple myeloma is considered incurable, all patients should be started on treatment with the goal of preventing further complications.

\section{Acknowledgements}

Not applicable.

\section{Funding}

No funding was received.

\section{Availability of data and materials}

The datasets used and/or analysed during the present study are available from the corresponding author on reasonable request.

\section{Authors' contributions}

SMa, conceived and designed the report, and wrote the manuscript. SMu collected and analysed the data, and contributed to writing the manuscript. Both authors read and approved the final manuscript.

\section{Ethics approval and consent to participate}

The present study was performed in accordance with the University of the Witwatersrand Human Research Ethics protocol.

\section{Patient consent for publication}

Written consent was obtained for the publication of this case report and any accompanying images. A copy of the written consent is available for review on reasonable request.

\section{Competing interests}

The authors declare that they have no competing interests.

\section{References}

1. Dezube BJ, Aboulafia DM and Pantanowitz L: Plasma cell disorders in HIV-infected patients: From benign gammopathy to multiple myeloma. AIDS Read 14: 372-374, 377-379, 2004

2. Roodman GD: Mechanisms of bone metastasis. N Engl J Med 350: 1655-1664, 2004.

3. Longo DL and Anderson KC: Plasma cell disorders. In: Harrison's principles of internal medicine. Kasper DL, Braunwald E, Fauci AS, Hauser SL, Longo DL and Jameson JL (eds). 16th edition. McGraw-Hill, New York, NY, pp657-658, 2005.

4. Van Riet I: Homing mechanisms of myeloma cells. Pathol Biol (Paris) 47: 98-108, 1999.

5. The International Myeloma Working Group: Criteria for the classification monoclonal gammopathies, multiple myeloma and related disorders: A report of the international myeloma working group. Br J Haematol 121: 749-757, 2003.

6. Knobel D, Zouhair A, Tsang RW, Poortmans P, Belkacémi Y, Bolla M, Oner FD, Landmann C, Castelain B and Ozsahin M; Rare Cancer Network: Prognostic factors in solitary plasmacytomas of the bone: A multicenter rare cancer network study. BMC Cancer 6: 118, 2006.

7. Ozsahin $M$, Tang RW, Poortmans P, Belkacémi Y, Bolla M, Dinçbas FO, Landmann C, Castelain B, Buijsen J, Curschmann J, et al: Outcomes and patterns of failure in solitary plasmacytoma: A multicenter rare cancer network study of 258 patients. Int J Radiat Oncol Biol Phys 64: 210-217, 2006.

8. Micheletti AR, Macedo AC, Silva GB, Silva AC, Silva-Vergara ML, Murta EF and Adad SJ: Benign and malignant neoplasias in 261 necropsies for HIV-positive patients in the period of 1989 to 2008 . Rev Inst Med Trop Sao Paulo 53: 309-314, 2011.

9. Diamond T, Levy S, Day P, Barbagallo S, Manoharan A and Kwan YK: Biochemical, histomorphometric and densitometric changes in patients with multiple myeloma: Effects of glucocorticoid therapy and disease activity. Br J Haematol 97: 641-648, 1997.

10. Nilsson-Ehle H, Holmdahl C, Suurküla M and Westin J: Bone scintigraphy in the diagnosis of skeletal involvement and metastatic calcification in multiple myeloma. Acta Med Scand 211: 427-432, 1982. 
11. Terpos E, Berenson J, Cook RJ, Lipton A and Coleman RE: Prognostic variables for survival and skeletal complications in patients with multiple myeloma osteolytic bone disease. Leukemia 24: 1043-1049, 2010.

12. Vincent Rajkumar S: Multiple myeloma: 2014 Update on diagnosis, risk-stratification, and management. Am J Hematol 89: 999-1009, 2014.

13. Grulich AE, Li Y, McDonald A, Correll PK, Law MG and Kaldor JM: Rates of non-AIDS-defining cancers in people with HIV infection before and after AIDS diagnosis. AIDS 16: 1155-1161, 2002

14. Ikezoe T, Saito T, Bandobashi K, Yang Y, Koeffler HP and Taguchi H: HIV-1 protease inhibitor induces growth arrest and apoptosis of human multiple myeloma cells via inactivation of signal transducer and activator of transcription 3 and extracellular signal-regulated kinase 1/2. Mol Cancer Ther 3: 473-479, 2004.

15. Carraway $\mathrm{H}$ and Ambinder RF: Plasma cell dyscrasia, Hodgkin lymphoma, HIV, and Kaposi sarcoma-associated herpesvirus. Curr Opin Oncol 14: 543-545, 2002.

16. Voelkerding KV, Sandhaus LM, Kim HC, Wilson J, Chittenden T, Levine AJ and Raska K Jr: Plasma cell malignancy in the acquired immune deficiency syndrome. Association with Epstein-Barr virus. Am J Clin Pathol 92: 222-228, 1989.
17. de Camargo Moraes P, Thomaz LA, Montalli VA, Junqueira JL, Ribeiro CM and Oliveira LB: Extramedullary plasmacytoma diagnosed in an HIV-positive patient by an unusual clinical presentation. Case Rep Dent 2016: 6305173, 2016.

18. De Groot JJB, Webb MJ, Raubenheimer JE, Struwig MC and Louw VJ: Concomitant HIV infection in newly diagnosed multiple myeloma patients is hard to recognise and should be tested for routinely in areas of high endemicity. S Afr Med J 107: 781-787, 2017.

19. Cauda R, Lucia MB, Marasca G, Rutella S, Petrucci MT, La Verde $G$ and Gastaldi R: Beneficial effect of highly active antiretroviral therapy (HAART) in reducing both HIV viral load and monoclonal gammopathy. Eur J Haematol 63: 134-135, 1999.

20. Gimeno LSE, Abella E, Perez-Vila E, Cervera M, Montero M, Gimenez MT, Knobel H and Besses C: Complete remission of smoldering myeloma in a HIV patient after highly antiretroviral therapy. Haematologica 92 (Suppl 2): S485, 2007.

(7)(9) This work is licensed under a Creative Commons Attribution-NonCommercial-NoDerivatives 4.0 International (CC BY-NC-ND 4.0) License. 